\title{
Mechanical and structural properties of weak snow layers measured in situ
}

\author{
Paul M. B. Föhn, Ghristian Camponovo, Georges Krüsi \\ Swiss Federal Institute for Snow and Avalanche Research, CH-7260 Davos Dorf, Switzerland
}

\begin{abstract}
Weak layers such as buried surface hoar or depth hoar frequently form the failure plane of slab avalanches. Therefore, the mechanical properties of such layers in relation to their snow structure have been investigated. Since it is difficult to transport samples containing a weak layer into cold rooms, the mechanical measurements have to be made in situ.

We investigate strain-rate dependency of shear strength by measuring concurrently strength, deformation and acceleration, using a digital force gauge attached to a $0.05 \mathrm{~m}^{2}$ shear frame to which an accelerometer and a displacement sensor are fixed. In doing so, a dynamic force comparable to a driving skier is applied. The measurements cover a strainrate range $10^{-2}$ to $1 \mathrm{~s}^{-1}$. The samples fail in a brittle manner. The shear-strength values cover the range $0.2-2.8 \mathrm{kPa}$. The dataset is also used to approximate the coefficient $G$, the shear modulus, for different weak layers.

The snow structure has been analysed macroscopically in the field and for some layers representative snow samples have been extracted in order to prepare, in the cold laboratory, single-sided serial planes with cuts every $0.1 \mathrm{~mm}$ recorded by video. The analysis of these snow samples should have given the relation between some mechanical properties (strength, strain) and the structural properties. Due to basic problems in defining the connection between complex snow grains (e.g. surface hoar), we were unable to complete this part in due time. Only preliminary results on this aspect are presented here. Based on our long-term database, containing macroscopic structural and strength data of weak layers, a relationship between snow type and shear strength has been established.
\end{abstract}

\section{INTRODUGTION}

Weak snow layers frequently fail in shear, resulting in the release of slab avalanches. The traditional shear-frame technique, yielding the shear strength of weak layers, has been widely used for avalanche forecasting (Roch, 1966; Perla, 1977; Föhn, 1987; Jamieson, 1995). However, the stress-strain and the stress-strain-rate relationships have not been measured concurrently until now, even though it is known that the strain and the strain rate are decisive for snow strength and hence for slab formation. The main objective of this work was to describe how snow containing weak layers responds to a shear stress applied rapidly by pulling a shear frame comparable to dynamic loading by skiers. The shearframe tests were made in situ, because snow samples containing weak layers or interfaces can rarely be transported into a cold laboratory and prepared for mechanical measurements without rupturing.

The second objective of this work was to measure the shear strength of various types of snow, usually present in weak layers, and to relate the strength to both the snow macro- and microstructure. The relationship between snow structure and mechanical behaviour is still not well known as Dent (1995) and Johnson (1995) recently pointed out. To assess the strength-macrostructure relationship, we analysed our long-term database containing macroscopic structural properties and measured shear-strength values of weak layers. To explore the strength-microstructure relationship, we report on some recent preliminary microstructural analysis of weak layers.

\section{EXPERIMENTAL PROGEDURES}

The instrumental set-up consisted of a $0.05 \mathrm{~m}^{2}$ shear frame to which an accelerometer and a displacement sensor were attached. The frame is embedded in the snow above the weak layer then pulled by hand to failure (Figs 1 and 2). The shearing was done in two modes, either within some

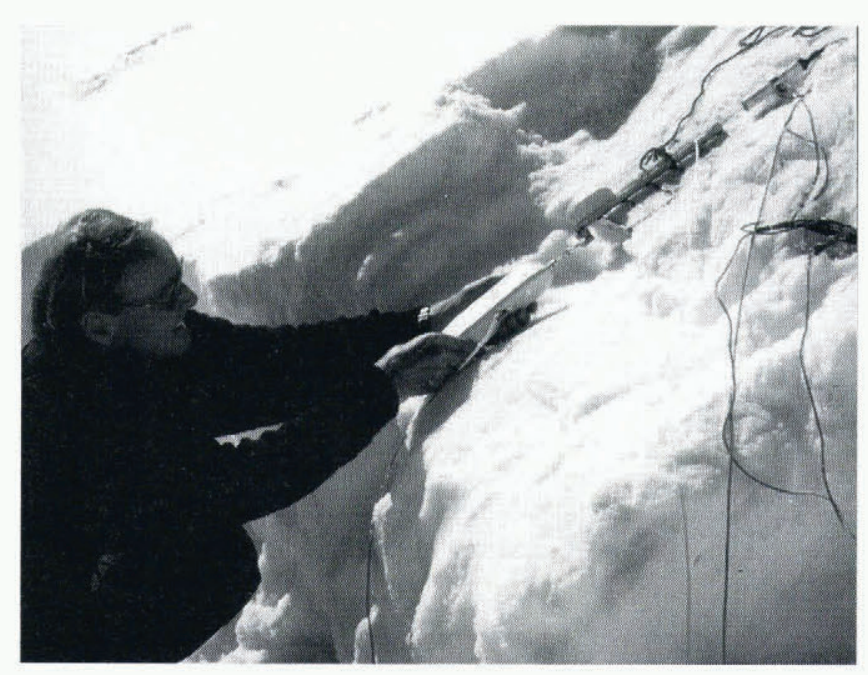

Fig. 1. Shear-frame measurement of a weak layer in situ. The shear-frame position in the snow and the mounted accelerometer on top of the frame are visible in the centre of the picture. The displacement meter is visible in the upper right corner of the picture. 
tenths of a second (called "fast") or within 1-3s (called "slow") in order to obtain a possible loading-rate effect and to simulate the range of loading by a skier (Schweizer and others, 1995). Acceleration, displacement and applied force were measured continuously during a test and recorded on a laptop computer. Tests were done under a fairly constant normal pressure of $250 \mathrm{~Pa}$, due to the weight of the shear frame with the sensors and of the snow contained in the shear frame. The instrumental set-up and the measuring procedures have been described in detail by Föhn and Camponovo (1997). During 12 field campaigns in the winter 1995-96, 11 weak layers and one interface were investigated and nearly 200 measurements were made in situ. Before each test, a full snow profile was made and the weak layers identified.

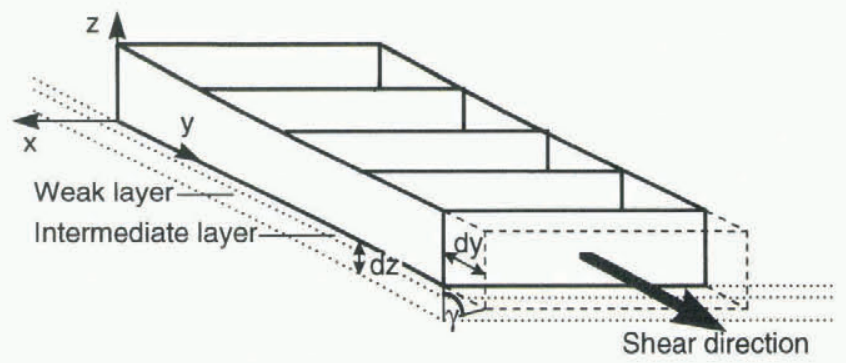

Fig. 2. Schematic of the shear frame, showing snow layering and definitions of axes. Layer thickness ( $\mathrm{d} z)$, displacement $(\mathrm{d} y)$ and shear angle $(\gamma)$ are labeled for reference.

\section{RESULTS}

\section{Stress-strain and stress-strain-rate relationship}

Figure 3 shows typical shear stress-strain curves for three weak layers. The results demonstrate that the shear stress increases almost linearly with the strain until the weak layer breaks, at which point the stress decreases abruptly. This lin-

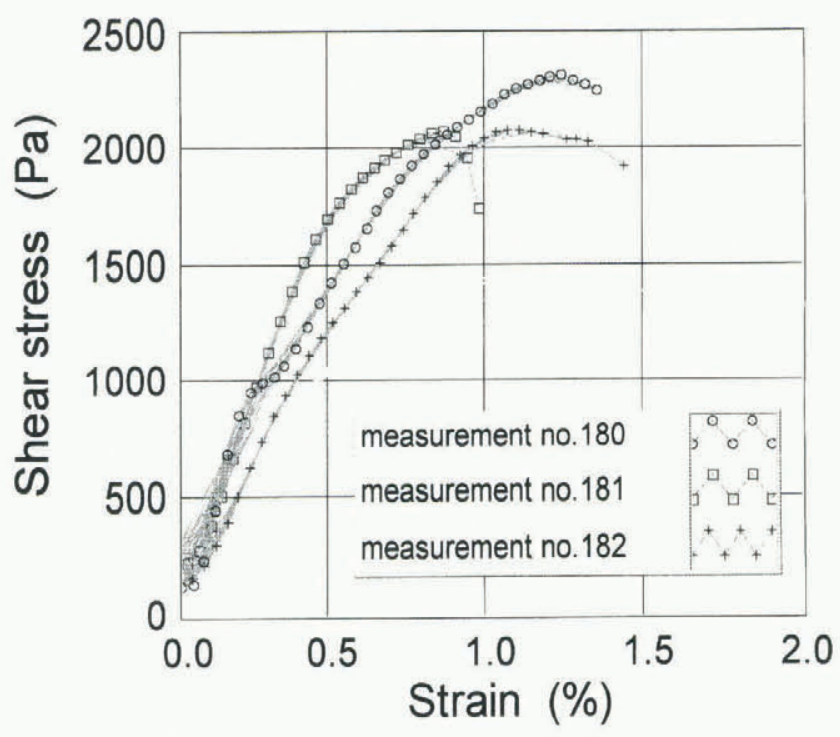

Fig. 3. Three typical shear stress-strain curves, showing the almost linear rise of the stress-strain curve and the peak stress. Strain rates at rupture are $0.92,0.58$ and $0.76 \mathrm{~s}^{-1}$, respectively. Measuring date is 29 March 1996 (A).

ear rise to a maximum stress at failure shows that the weak layers behave like a "brittle" material. McClung (1977) reported such behaviour 20 years ago and recently Fukuzawa and Narita (1993) have shown that brittle fracture in an artificially prepared depth-hoar layer typically takes place at a shear strain rate higher than $1-5 \times 10^{-4} \mathrm{~s}^{-1}$. All our shear measurements for weak layers were at strain rates of $10^{-2}$ to $1 \mathrm{~s}^{-1}$ and all layers showed brittle behaviour. The results of all the tests are given in Table 1, including the shear strength, the displacement and the strain rate.

Because the instrumentation and the procedure were new in the winter 1995-96, instrumental difficulties and sample rupturing occurred during many tests. Only about $50 \%$ of the data points could be used for the detailed analysis. These are shown in Figure 4, where the shear stress

Table 1. Snow structure and mechanical properties of 11 weak layers and one interface together with date of measurement for identification purposes

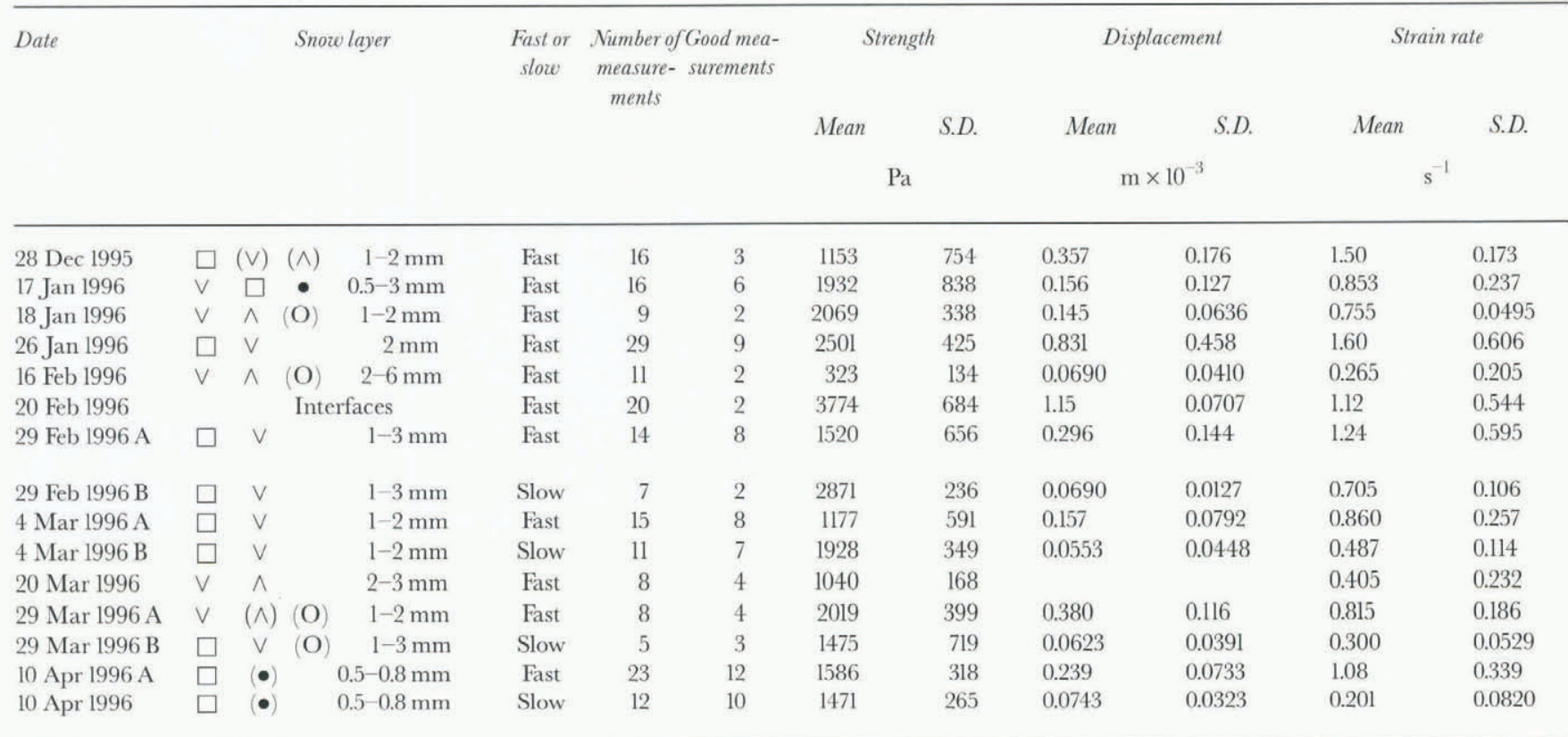


is plotted against strain for 11 weak layers. The points are scattered because:

(1) The measurements were not made under controlled conditions as in a cold room, so both temperature and the strain rate varied slightly from one test to another.

(2) The measured weak layers consisted of various snow types and were, as always, variable in space.

In spite of the scatter, Figure 4 shows that the fracture stress increases with increasing strain.



$\begin{array}{lll}-28.12 .1995 & +17.01 .1996 & \Delta 18.01 .1996 \\ * 26.01 .1996 & -16.02 .1996 & -29.02 .1996 \mathrm{~A} \\ -29.02 .1996 \mathrm{~B} & +04.03 .1996 \mathrm{~A} & \square 04.03 .1996 \mathrm{~B} \\ -29.03 .1996 \mathrm{~A} & \Delta 29.03 .1996 \mathrm{~B} & \times 10.04 .1996 \mathrm{~A}\end{array}$

Fig. 4. Shear stress-strain relationship for 13 layers. The scattering of the individual layer points is mainly due to slightly changing measuring and snow conditions in the field (sample preparation, pull action, temperature differences, snow inhomogeneities).

However, because the stress-strain curves of Figure 3 imply a quasi-linear elastic behaviour up to fracture, our experimental data can be described by the linear constitutive equation for plane shear (Sommerfeld, 1978)

$$
\tau=G \gamma
$$

where $\tau$ is the shear stress, $\gamma$ is the shear angle $(\gamma=$ $\tan (\mathrm{d} y / \mathrm{dz}) \approx \mathrm{dy} / \mathrm{dz}$ for small $\mathrm{d} y)$ and $G$ is the shear modulus. Values of $G$ were determined by linear interpolation from 0 to $50 \%$ of the fracture stress. The shear modulus $G$ can be related to the more common Young's modulus $E$

$$
E=2(1+\nu) G
$$

where $\nu$ is the Poisson's ratio. For dry low-density snow, the Poisson's ratio is generally small. Salm (1971) and Oh'izumi and Huzioka (1982) determined, for dry coherent snow of similar density and temperature, Poisson's ratios between 0.01 to 0.15 . If we assume for our weak layers $\nu \approx 0.1$, we may approximate the Young's modulus by

$$
E \approx 2 G,
$$

i.e. we may compare our values of $E$ with previous data. Table 2 lists values of the shear modulus $G$ determined for different weak layers on various dates and hence for various snow types and environmental conditions. The $G$ values cover the range from 0.1 up to $0.6 \mathrm{MPa}$. Using Equation (3), corresponding values of the Young's modulus would be
Table 2. Snow structure and $G$ moduli, calculated from the stress-strain relationship for various weak layers using different snow types. The shear strain is determined by the accelerometer measurements (acc.) or by the displacement sensor (displ.). Comparisons of the two methods have been described by Föhn and Camponovo (1997)

\begin{tabular}{lcccccc}
\hline Date & \multicolumn{3}{c}{ Grain types } & Method & G modulus & S.D. \\
& & & & & $\mathrm{MPa}$ \\
& & & & & \\
& & & & & \\
\hline 28 Dec 1995 & $\square$ & $(\vee)$ & $(\wedge)$ & acc. & 0.13 & 0.08 \\
17 Jan 1996 & $\vee$ & $\square$ & $\bullet$ & acc. & 0.22 & 0.09 \\
18 Jan 1996 & $\vee$ & $\wedge$ & $(\mathrm{O})$ & acc. & 0.59 & 0.21 \\
26 Jan 1996 & $\square$ & $\vee$ & & acc. & 0.11 & 0.03 \\
29 Feb 1996 A & $\square$ & $\vee$ & & acc. & 0.41 & 0.36 \\
20 Mar 1996 & $\vee$ & $\wedge$ & & displ. & 0.37 & 0.09 \\
29 Mar 1996 A & $\vee$ & $(\wedge)$ & $(O)$ & displ. & 0.21 & 0.05 \\
29 Mar 1996 B & $\square$ & $\vee$ & $(O)$ & displ. & 0.18 & 0.07 \\
& & & & & & \\
\hline
\end{tabular}

between 0.2 and $1.2 \mathrm{MPa}$. These values compare reasonably with values for similar density, if the different snow types (dry, coherent snow) of the former studies are taken into consideration (Shapiro and others, 1997). Our values are smaller by a factor of 0.5 than those published. This seems reasonable, because $E$ values for granular snow with low cohesion are expected to be smaller than those for dry coherent snow (Mellor, 1975).

\section{Shear strength of various weak layers and snow types}

In this second part, the strength of various weak layers and snow types is analysed in relation to the macro- and microscopic structure. The data from our long-term database include macroscopic structural parameters such as grain shape, mean grain-size, layer thickness, snow temperature, overburden snow pressure, age and of course mean shear strength (average of about ten measurements per layer). Data for 169 weak layers and for 201 interfaces are available. Thelarge dataset allows a relationship between the shear strength and the structural snow parameters of weak layers to be developed.

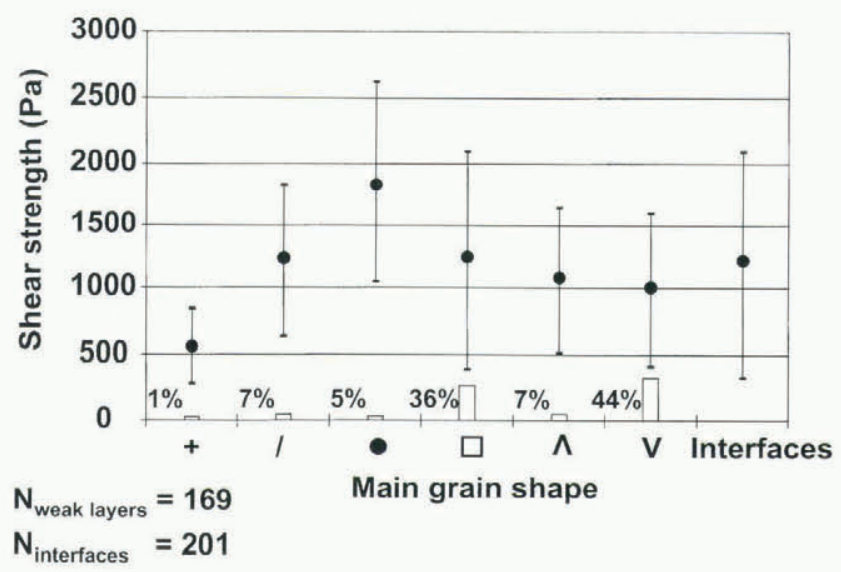

Fig. 5. In-situ measured shear strength as a function of the macroscopic main grain shape. Each sample was classified by the majority of grains, which were in the given snow-shape class (Colbeck and others, 1990). The percentage indicates the occurrence of such main grain shapes in our long-term database. Interfaces are boundaries between two thick layers, where no distinct, thin weak layer has been observed. 
Figure 5 shows the shear-strength data as a function of grain shape. The strength data have been corrected for size effects and details have been given by Föhn (1987). The data suggest that lower shear-strength values are associated with more "crystalline" grains. These are grains showing euhedral features like facets, striations or dendrite branches. Rounded grains showed the highest shear strength. The large scatter bars for the data can be explained by the fact that pure grain types have almost never been observed and that the layers have different temperatures, age and grainsizes. In most cases, a combination of various shapes (e.g. metamorphic stages between small rounded grains and faceted grains or surface hoar and melt-freeze grains) have been observed but only the main shape is classified in Figure 5. The relative distribution of each type of grain is shown at the bottom of Figure 5. The percentages indicate that in our climate weak layers consist mainly of surface hoar, faceted crystals and depth hoar (Föhn, 1993). Figure 5 represents, for comparison, also the shear strength of weak interfaces, i.e. in these cases, a distinct thin layer of a given snow type could not be detected by visual inspection. The mean temperature of the analysed weak layers or interfaces was $-5.5^{\circ} \pm 2.7^{\circ} \mathrm{C}$. The total temperature range was $-2.6^{\circ}$ to $-12.0^{\circ} \mathrm{C}$. This total temperature range could be responsible for a strength variation between 20 and $25 \%$, at least for fine-grained snow, according to data of Salm (1971) and Schweizer (1997).

Until now, only the relationship between macrostructure and mechanical parameters of weak layers has been analysed. In order to explain at least some aspects of the mechanical behaviour, we decided to start an analysis of microstructural parameters for one sample (26 January 1996).

The sample was serially sectioned into 46 single-sided serial planes with an area of $4.5 \times 4.2 \mathrm{~cm}^{2}$. The section planes were cut after impregnating the sample with dark dyed, liquid diethyl phtalate, then freezing the liquid. The section planes were prepared using a Policut Ultramiller and a fibre-optic ring-light source to illumine the sample. Then, the structure was recorded by a video camera. The sample-preparation procedure has been described in more detail by Good (1989).

As Figure 6 shows, this sample contained an upper weak layer (uwl), an intermediate layer (il) that was not weak and a lower weak layer (lwl). The upper weak layer (uwl) consisted of surface hoar of $2 \mathrm{~mm}$ size. It was $3 \mathrm{~mm}$ thick. The window in the middle of Figure 6 shows part of the intermediate layer (il). It contains rounded and angular grains of $0.5-1 \mathrm{~mm}$. The lowest window shows the lower weak layer (lwl). Shear tests were done on this layer. It consisted of sur- face hoar and faceted grains with a mean diameter of $2 \mathrm{~mm}$. The layer was about $7 \mathrm{~mm}$ thick. The shear strength was measured as $2500 \pm 425 \mathrm{~Pa}$.

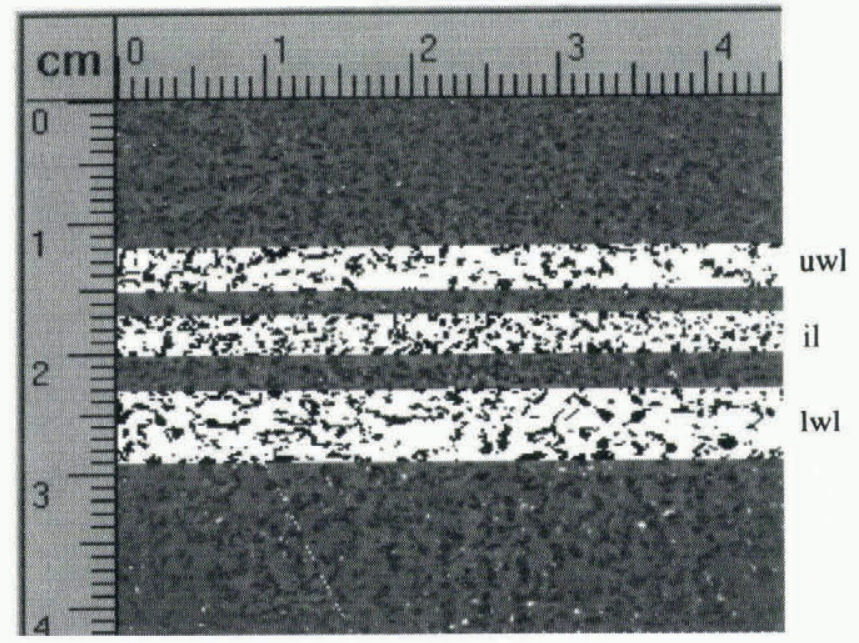

Fig. 6. A serial plane section of sample (26 January 1996) showing two weak layers and an intermediate layer. The microstructural snow parameters for the two weak layers, plus the non-weak (intermediate) layer are given in Table 3. (uwl, upper weak layer; il, intermediate, fine-grained snow layer; lwl, lower weak layer; ice $=$ dark).

Some of the microstructural characteristics of the three layers are given in Table 3 . The point densities show that the two weak layers have a lower density than the fine-grained intermediate layer. This is consistent with field observations that suggest weak layers are of lower density than surrounding layers but it is the first time we have been able to quantify the difference. The most remarkable thing is the fact that, by microstructural analysis, we are able to obtain densities of layers which are no thicker than a few millimetres and which therefore cannot be measured by the usual field methods. The other micromechanical characteristics in Table 3 do not differentiate the weak layers quite as clearly as density. The two different particle diameters, each determined by separate methods, do not correspond well with the macroscopically determined particle diameters. The calculated diameters for the weak layers are almost $100 \%$ smaller than those estimated macroscopically in the field. The diameters of the intermediate layer, in contrast, correspond quite well to the field estimation. This is not surprising,

Table 3. Some microstructural characteristics of snow layers measured on 26 January 1996 and given in Figure 6

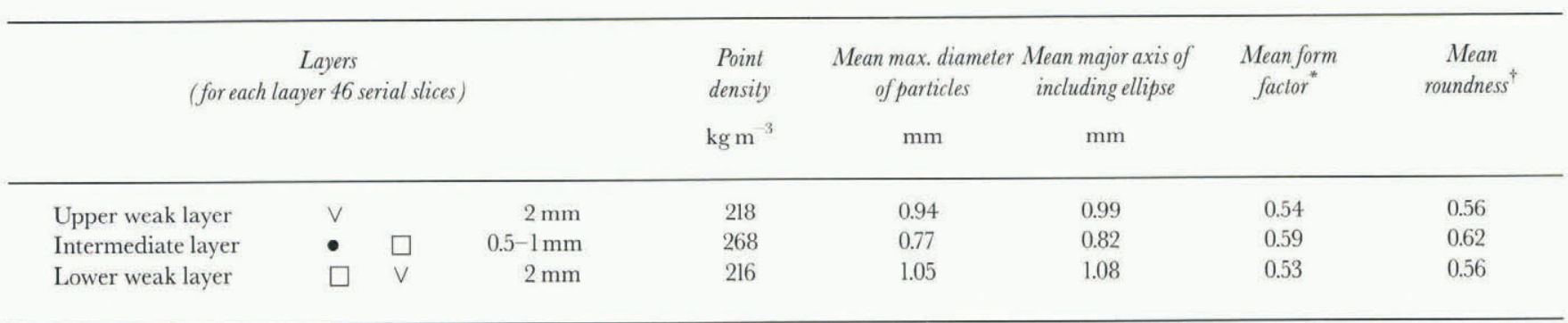

Particles with maximum diamter $<0.2 \mathrm{~mm}$ are excluded.

* Form factor $=4 \times \pi \times$ area/perimeter ${ }^{2}$ (Russ, 1994); equals 1/dendricity (Lesaffre and others, 1997).

${ }^{+}$Roundness $=4 \times$ area $/ \pi \times$ max. diameter ${ }^{2}$ (Russ, 1994). 


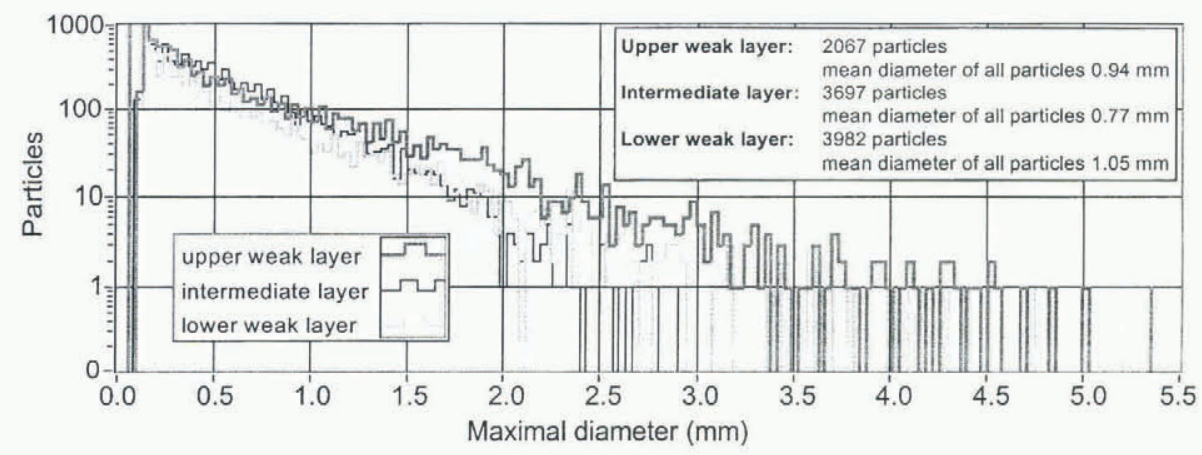

Fig. 7. Frequency distribution of the maximum grain diameters for the three layers shown in Figure 6. Only the two "tails" of the weak layers extend further than $3 \mathrm{~mm}$, a feature which may be characteristic for weak layers containing large surface-hoar crystals.

because the weak layers consist mainly of large snow crystals (several millimetres), which are cut into smaller particles during the preparation of the section planes. According to Underwood (1970) and DeHoff (1983), we can only reconstruct three-dimensional structures, e.g. real diameters, from two-dimensional section planes if the elements are of regular geometric shapes or if detailed assumptions and definitions about the three-dimensional properties are obtainable. As we have not been able to tackle these problems in this preliminary study, we give in Figure 7 an additional feature of structural analysis which shows part of the difficulty. The frequency distribution of the diameters of the three layers in the section planes shows clearly that any kind of "mean" is debatable. They suggest that two-dimensional cuts of a weak layer have large distribution "tails". The form and roundness factors in Table 3, defined according to Russ (1994), describe the shape differences of the snow grains. The mean form factor, which is the inverse version of the dendricity used by Lesaffre and others (1997), describes the tendency of grains to be dendritic like stellar new snow: the smaller the values, the more dendritic the snow. Even so, this dendritic tendency is larger for our two weak layers than for the intermediate layer, i.e. the two form factors are smaller than those for the intermediate layer, the differences are so small that this parameter seems to be a poor form factor for this type of grain. The last parameter in Table 3, the roundness, describes the tendency of particles to be "symmetric". Here again, the rather rounded particles of the intermediate layer are somewhat more symmetric than the complex, partly feathery crystals in the two weak layers but the differences are too small to promise a good potential for clear identification. These factors seem to be unsuited for differentiating weak from non-weak layers, at least by using the method of section planes. These factors may be informative when single grains are described (Lesaffre and others, 1997). In order to describe the most significant structural parameters for the mechanical behaviour of snow grains, three-dimensional reconstructions have to be performed and new definitions will have to be developed. These may include measurements related to the number and area of bonds.

\section{CONGLUSIONS}

In-situ shear-frame measurements are well suited to determining some of the important mechanical parameters of thin weak layers or interfaces. Due to their fragility, samples containing thin weak layers can seldom be transported into cold laboratories for measurement. By applying a shear force using a rather fast stroke (pull), samples fail in a brittle manner. Strain rates are between $10^{-2}$ and $1 \mathrm{~s}^{-1}$, and correspond roughly to the loading range of a skier. Weak layers frequently form the failure plane of snow-slab avalanches and have a shear strength that ranges from 0.2 to $3 \mathrm{kPa}$, depending on snow type. Young's modulus, calculated from the measured stress-strain curves, ranges from 0.2 up to $1.2 \mathrm{MPa}$, assuming a Poisson's ratio of 0.1 , according to previous studies. These values of Young's modulus compare reasonably with published values of other dry-snow types. The relationship between measured shear strength and grain shape, determined macroscopically, shows it is mainly grains containing euhedral features like facets, striations or dendritic branches that show low shear strength. Microstructural analysis of weak layers does not uniquely identify the layers, except that their density is generally lower than the surrounding snow. Mean diameters and measures of roundness and dendricity do not differentiate sufficiently between the weak layers and the fine-grained layers. In addition, such microstructural analysis requires assumptions and definitions about three-dimensional properties. New methods based on the three-dimensional connection between grains, which is most likely important for the mechanical behaviour, will need to be derived.

\section{ACKNOWLEDGEMENTS}

We are very grateful to $\mathrm{K}$. Plattner for his help in analysing primarily the snow structure. Thanks are also due to C. Fierz and J. Schweizer for stimulating discussions, and to M. Sturm for his helpful comments and suggestions.

\section{REFERENCES}

Colbeck, S. C. and 7 others. 1990. The international classification for seasonal snow on the ground. Wallingford, Oxon, International Association of Scientific Hydrology. International Commission on Snow and Ice.

DeHoff, R. T. 1983. Quantitative serial sectioning analysis: preview. 7. Microsc., 131 (3), $259-263$.

Dent, J. 1995. Mechanical properties of snow. In Proceedings of the Workshop: Future Directions in Snow and Ice Research, 3-6 October 1995. Gallatin Gateway, MT, U.S. Army Research Office, 17-18.

Föhn, P. M. B. 1987. The stability index and various triggering mechanisms. International Association of Hydrological Sciences Publication 162 (Symposium at Davos 1986 - Avalanche Formation, Movement and Effects), 195-214.

Föhn, P. M. B. 1993. Characteristics of weak snow lavers or interfaces. IIn Armstrong, R., ed. ISSW'92. A Merging of Theory and Practice. International Snow Science Workshop, 4 8 October 1992, Breckenridge, Colorado. Proceedings. Denver, CO, Avalanche Information Center, 160-170.

Föhn, P. and C. Camponovo. 1997. Improvements by measuring shear 
strength of weak layers. In ISSW'96. International Snow Science Workshop, 6-10 October 1996, Banff, Alberta. Proceedings. Revelstoke, B.C., Canadian Avalanche Association, 158-162.

Fukuzawa, T. and H. Narita. 1993. An experimental study on mechanical behavior of a depth hoar under shear stress. In Armstrong, R., ed. ISSW'92. A Merging of Theory and Practice. International Snow Science Workshop, 4- 8 October 1992, Breckenridge, Colorado. Proceedings. Denver, CO, Avalanche Information Center, 171-175.

Good, W. 1989. Laboratory techniques for the characterization of snow structure. In Hunt, J. and T. D. Guyenne, eds. International Workshop on Physics and Mechanics of Cometary Materials, October 9-11, 1989, Münster, Westfalia, Germany. Proceedings. Noordwijk, European Space Agency, 147-151. (ESA SP-302.)

Jamieson, J. B. 1995. Avalanche prediction for persistent snow slabs. (Ph.D. thesis, University of Calgary,

Johnson, J. B. 1995. Quasi-static and dynamic mechanical properties of snow. In Proceedings of the Workshop: Future Directions in Snow and Ice Research, 3-6 October 1995. Gallatin Gateway, MT, U.S. Army Research Office, 4-5.

Lesaffre, B., E. Pougatch and E. Martin. 1997. Détermination objective des caractéristiques des grains de neige à partir d'images. In Réunion du 6-7 mars 1997, Grenoble. Grenoble, Société Hydrotechnique de France, 1-7.

McClung, D. M. 1977. Direct simple shear tests on snow and their relation to slab avalanche formation. f. Glaciol., 19(81), 101-109.

Mellor, M. 1975. A review of basic snow mechanics. International Association of Hydrological Sciences Publication 114 (Symposium at Grindelwald 1974-Snow Mechanics), 251-291.

Oh'izumi, M. and T. Huzioka. 1982. Studies of the behaviour of a snow cover on a mountain slope. 11. Poisson's ratio of snow. Low Temp. Sci., Ser. A 41, 43-53.

Perla, R. 1977. Slab avalanche measurements. Can. Geotech. 7., 14(2), 206-213.

Roch, A. 1966. Les variations de la résistance de la neige. International Association of Scientific Hydrology Publication 69 (Symposium at Davos 1965Scientific Aspects of Snow and Ice Avalanches), 86-99.

Russ, J. C. 1994. The image processing handbook. Second edition. Boca Raton, FL, CRC Press Inc.

Salm, B. 1971. On the rheological behavior of snow under high stresses. Contrib. Inst. Low Temp. Sci., Ser. A 23, 1-43.

Schweizer, J. 1997. Preliminary results on controlled shear experiments. In ISSW'96. International Snow Science Workshop, 6-10 October 1996, Banff, Alberta. Proceedings. Revelstoke, B.C., Canadian Avalanche Association, 195-197.

Schweizer, J., C. Camponovo, C. Fierz and P. M. B. Föhn. 1995. Skier triggered slab avalanche release - some practical implications. In Sivardière, F., ed. Les apports de la recherche scientifique à la sécurité neige, glace et avalanche. Actes de Colloque, Chamonix 30 mai-3 juin 1995. Grenoble, Association Nationale pour l'Étude de la Neige et des Avalanches (ANENA), 309-315.

Shapiro, L. H., J. B. Johnson, M. Sturm and G. L. Blaisdell. 1997. Snow mechanics: review of the state of knowledge and applications. CRREL Rep. $97-3$.

Sommerfeld, A. 1978. Mechanik der deformierbaren Medien. Sixth edition. Thun and Frankfurt am Main, Verlag Harri Deutsch.

Underwood, E. E., ed. 1970. Quantitative stereology. Reading, MA, AddisonWesley Publishing Co. 